Marjorie J. Arca - John C. Krauss - Scott E. Strome

Mark J. Cameron • Alfred E. Chang

\title{
Diverse manifestations of tumorigenicity and immunogenicity displayed by the poorly immunogenic B16-BL6 melanoma transduced with cytokine genes
}

\begin{abstract}
We evaluated the in vivo response to the poorly immunogenic B16-BL6 (BL6) murine melanoma genetically altered to secrete interleukin-2 (IL-2), IL-4, interferon $\gamma(\mathrm{IFN} \gamma)$ and granulocyte/macrophage-colony-stimulating factor (GM-CSF). Three parameters were evaluated: (1) tumorigenicity, (2) vaccination of naive animals, and (3) assessment of antitumor reactivity of $\mathrm{T}$ cells derived from tumor-draining lymph nodes (TDLN). Secretion of IL-2 abrogated the tumorigenicity of BL6, while IFN $\gamma$ and IL-4 partially reduced tumorigenicity, and GM-CSF had no effect. Protective immunity to wild-type tumor challenge could not be achieved by vaccination with irradiated cytokine-secreting tumors, although IL-2 and IL-4 secretion appeared to retard the growth of the challenge inoculum significantly. An alternative method to evaluate the immunogenicity of the cytokine-secreting tumors was to measure the ability of $\mathrm{T}$ cells obtained from TDLN to mediate regression of wild-type tumor in adoptive immunotherapy. Neither IL-2 nor IFN $\gamma$ secretion resulted in the induction of immune T cells. By contrast, GM-CSF and IL-4 secretion were found to induce immune $\mathrm{T}$ cells in the TDLN with GM-CSF being superior to IL-4. The combined secretion of GM-CSF and IL-4 did not lead to enhanced induction of immune $\mathrm{T}$ cells. GM-CSF secretion was found to upregulate $\mathrm{B} 7-1$ expression in TDLN, consistent with an increase in the population of antigen-presenting cells. These studies demonstrated that reduced tumorigenicity by cytokine secretion did not correlate with increased immunogenicity. With the cytokines examined, there was limited capability of developing protective immunity
\end{abstract}

M. J. Arca • M. J. Cameron • A. E. Chang $(\square)$

Department of Surgery, University of Michigan,

1500 E. Medical Center Drive, Ann Arbor, MI 48109, USA

Fax: 313936 5830; e-mail aechang@umich.edu

J. C. Krauss

The Cleveland Clinic Foundation, Cleveland, Ohio, USA

S. E. Strome

Department of Otolaryngology, University of Michigan, Ann Arbor, Mich., USA against the BL6 tumor. Nevertheless, GM-CSF and IL-4 secretion significantly enhanced $\mathrm{T}$ cell immune reactivity to the poorly immunogenic BL6 tumor.

Key words Melanoma $\cdot$ Vaccine $\cdot$ Adoptive immunotherapy $\cdot$ Gene therapy $\cdot$ Cytokines

\section{Introduction}

It is evident that both experimental animal and spontaneous human tumors express antigens that can act as epitopes to different arms of the host immune response. Yet microscopic tumors are able to evade these immunological responses, to progress eventually and cause the death of the host. Many theories have been proposed as to why the host fails to recognize tumors. One theory is that expression of major histocompatibility complex (MHC) molecules by tumor cells is diminished [1-3]. Another hypothesis is deficient antigen processing and presentation by antigenpresenting cells (APC) within the tumor [4, 5]. Other theories describe a variety of mechanisms involving active suppression of the immune response by progressive tumors either through the elaboration of suppressive cytokines [6, 7] or through defects in $T$ cell signalling and altered cytokine production $[8-10]$.

Within the past several years, investigators have utilized molecular techniques to modify tumor cells genetically in order to enhance host responsiveness to native tumor antigens. The introduction of specific cytokine genes into tumor cells has been reported to up-regulate MHC antigen expression on tumor cells [11-12], enhance antigen presentation by the tumor itself or by professional APC [13-15], provide deficient helper factors, or counteract $T$ cell signalling defects in the tumor-bearing host [16-18]. This study explores the role of secretion of four different cytokines: interleukin-2 (IL-2), IL-4, interferon $\gamma$ (IFN $\gamma$ ), and granulocyte/macrophage-colony-stimulating factor (GM-CSF) on the immunobiology of a poorly immunogenic murine tumor, B16-BL6 (BL6). We have focused on 
this tumor as a pre-clinical model because of its similarities to human malignancies that have been postulated to be poorly immunogenic. Specifically, it lacks MHC molecule expression [2], is unresponsive to IL-2 therapy [1], is incapable of eliciting functional tumor-infiltrating lymphocytes [19], cannot induce systemic immunity using standard experimental vaccination procedures [20], and spontaneously metastasizes from an intradermal tumor inoculation $[21,22]$.

Using the BL6 tumor model, we have evaluated three in vivo parameters of host immune responsiveness to clones of BL6 tumor genetically modified to secrete selected cytokines. These parameters include tumorigenicity, the ability to generate immune animals by immunization, and immunotherapy of established tumor by the adoptive transfer of tumor-draining lymph node (TDLN) cells. As will become evident in this report, the immunogenicity of the cytokinesecreting tumor clones defined by these parameters is distinctly different.

\section{Materials and methods}

\section{Mice}

Female C57BL/6J (B6) mice, 6 weeks old, were purchased from the Jackson Laboratory, Bar Harbor, Me. The mice were maintained in specific-pathogen-free conditions and were used for experiments at age 8 weeks or older.

\section{Tumor}

The B16-BL6 melanoma is a tumor of spontaneous origin that has been studied extensively. The tumor was originally provided by Dr. E. Gorelick (Pittsburgh Cancer Institute, Pittsburgh, Pa.). This tumor line has been cloned by limiting dilution and has previously been designated D5 by our laboratory [15]. For the purposes of this report, D5 has been used as the wild-type BL6 tumor and the line used to generate cytokine-secreting transfectants. Tumor cells were maintained by serial in vitro passage in complete medium. Complete medium consists of RPMI-1640 medium supplemented with $10 \%$ heat-inactivated fetal calf serum, $0.01 \mathrm{mM}$ non-essential amino acids, $1 \mu \mathrm{M}$ sodium pyruvate, $2 \mathrm{mM}$ fresh L-glutamine, $100 \mu \mathrm{g} / \mathrm{ml}$ streptomycin, $100 \mathrm{U} / \mathrm{ml}$ penicillin, $50 \mu \mathrm{g} / \mathrm{ml}$ gentamicin, $0.5 \mu \mathrm{g} / \mathrm{ml}$ fungizone (all reagents from Gibco, Grand Island, N.Y.) and $10 \mu \mathrm{M}$ 2-mercaptoethanol. For intravenous (i.v.) and intradermal (i.d.) tumor inoculation, adherent tumor cells were removed from the flask by trypsin and washed in complete medium. Tumor cells were washed in Hank's balanced salt solution (HBSS) three times and resuspended in the appropriate volume of HBSS before administration to animals.

\section{Retroviral vector construction}

Plasmid DNA subcloning was carried out by standard techniques using reagents obtained from New England Biolabs (Tozer, Mass.) (Fig. 1). The cDNA for murine IFN $\gamma$ (a gift from Dr. L. Lanier, DNAX Institute, Palo Alto, Calif.) and GM-CSF (a gift from Dr. N. Gough, The University of Melbourne, Melborne, Australia) were mutated by the polymerase chain reaction (PCR) to include an $N c o$ I site at the initiation ATG and a BamHI site just $3^{\prime}$ to the termination codon. For MFG-IFN $\gamma$, the $5^{\prime}$ primer used was $5^{\prime}$-GCC-TAG-CTC-TGAGAC-CAT-GCA-CGC-TAC-ACA-CTG-C-3' and the $3^{\prime}$ primer was 5'-AAA-TAG-TGC-TGG-CAG-AAG-GAT-CCT-TAT-TCG-GAC-3' .

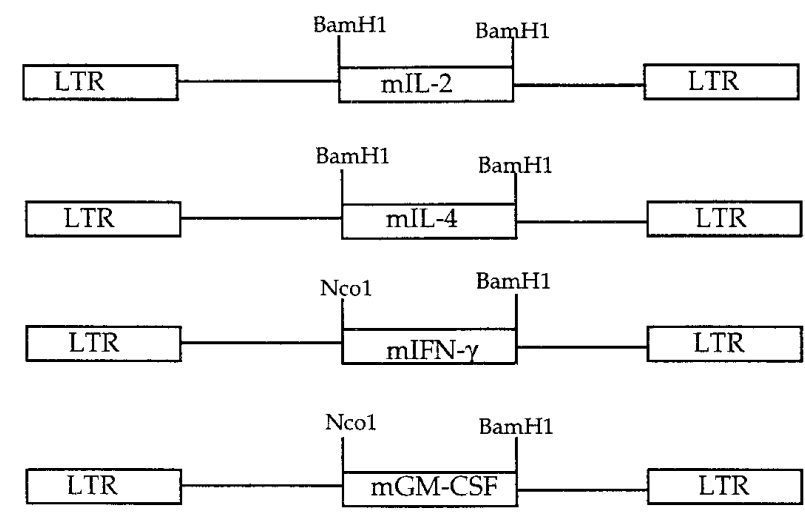

Fig. 1 Schematic map of retroviral constructs. LTR long terminal repeat, $m I L-2$ murine interleukin-2, $m G M$ - CSF murine granulocyte/ macrophage-colony-stimulating factor, $m I F N g$ murine interferon $\gamma$

For MFG-GM-CSF, the 5' primer used was 5'-GGC-TAA-GGT-CCTGAG-GAC-CAT-GGG-GCT-GCA-GAA-TTT-ACT-3'. The $3^{\prime}$ primer was 5'-GGA-TTC-AGA-GCA-GGC-CTG-GGC-TTC-CTC-A-3'. The mutated cDNA was directionally cloned into the NcoI and BamHI site of the retrovirus backbone MFG [14]. The coding region of the final cytokine vector was sequenced to ensure no inadvertent mutations had occurred during PCR. The MFG-GM-CSF vector and the MFG-IFN $\gamma$ vector were each co-transfected with the selectable marker pSV2Neo into $\psi$-crip cells with calcium precipitation and glycerol shock. Producer clones were isolated and screened for high-titer virus production by transfecting NIH 3T3 cells from the American Type Culture Collection (ATCC, Rockville, Md.), collecting 24-hour supernatants, and testing for cytokine secretion. Virus-containing supernatants from the cell clone producing the highest titer was used to transduce the BL6 tumor. The construction of MFG-IL-2 and MFG-IL-4 has been previously described [20]. Virus-containing supernatants were free of helper virus as determined by a sensitive provirus rescue assay with 2 weeks of amplification.

Genetic modification of tumor cells

Cytokine-secreting tumor cells were generated by splitting confluent BL6 cells 1:10, and transducing them with $5 \mathrm{ml}$ virus in the presence of polybrene $(8 \mu \mathrm{g} / \mathrm{ml})$. Transduced tumor cell clones were generated by limiting dilution and those with the highest level of cytokine production were chosen for further study.

Cytokine assays

Murine IL-4, IFN $\gamma$ and GM-CSF were assayed using commercially available enzyme-linked immunosorbent assay (ELISA) reagents from Pharmingen (San Diego, Calif.). For GM-CSF, a standard curve starting at $12.5 \mathrm{ng} / \mathrm{ml}$ with 11 serial twofold dilutions in duplicate was performed. For IFN $\gamma$ a standard curve starting at $1000 \mathrm{U} / \mathrm{ml}$ was established in the same fashion. Similarly, a standard curve starting at $100 \mathrm{ng} / \mathrm{ml}$ was used for IL-4 assay. A 2-ml sample of complete medium conditioned by $2 \times 10^{6}$ tumor cells for $24 \mathrm{~h}$ was assayed for cytokine content using this ELISA method. The IL-2-sensitive cell line, HT-2 (ATCC, Rockville, Md.), was used to determine IL-2 concentration. Conditioned medium was assayed for IL-2 content in a standard 3-(4,5-dimethylthiazol-2-yl)-2,5-diphenyltetrazolium bromide proliferation assay with recombinant IL-2, starting at $1000 \mathrm{U} /$ $\mathrm{ml}$, run in parallel. Tumors were tested every 3 months to ensure stable cytokine secretion. 
Flow-cytometric analysis

Cells were analyzed by indirect immunofluorescence using fluorescein-isothiocyanate (FITC)-conjugated mouse mAb to rat k-chain (MAR 18.5, Pharmingen, San Diego, Calif.), or with goat anti-(mouse Ig) (Cappel, Organon Teknika Corp., Durham, N.C.) depending on the species of primary mAb used. Primary mAb directed at the following epitopes were used: H-2Kb (28-13-3S), H-2D $\mathrm{K}^{\mathrm{b}}$ (28-14-8S), Iab (28-168S), Thy1.2 (30-H12), CD4 (L3T4), CD8 (2.43), and CD11b (M1/70, 15.11.5) (ATCC, Rockville, Md.). FITC-conjugated B7-1 mAb (1G10) was used for primary staining and obtained from Pharmingen (San Diego, Calif.). Routinely $(5-10) \times 10^{5}$ cells were stained and $10^{4}$ cells in each sample were analyzed. The percentage of positive cells was calculated by subtracting the background staining of the negative control.

\section{Tumorigenicity assessment}

Mice were inoculated intradermally (i.d.) with the indicated number of cells suspended in $0.1 \mathrm{ml}$ HBSS. The tumors were measured twice per week in two perpendicular dimensions with vernier calipers and the size was recorded as area in $\mathrm{mm}^{2}$.

\section{Immunization protocol}

Groups of mice were immunized with wild-type or cytokine-secreting tumors by the i.d. inoculation of $10^{6}$ irradiated (5000 Gy) tumor cells. This dose of irradiation has been previously documented to render BL6 non-tumorigenic. We and others have demonstrated that this amount of irradiation does not abrogate the secretion of cytokines from transduced tumor lines. After 4 weeks, the mice were subsequently challenged i.d. with $10^{5}$ viable wild-type BL6 cells at a separate site from the vaccine site. Tumor growth was monitored twice weekly and tumor size measured as described.

Tumor-draining lymph node (TDLN) cells

Samples containing $10^{6}$ wild-type or modified tumors in $0.1 \mathrm{ml}$ HBSS were injected i.d. in the flanks of syngeneic B6 mice. Nine days later, tumor-draining inguinal lymph nodes were harvested under sterile conditions. For the experiments with Corynebacterium parvum, $12.5 \mu \mathrm{g}$ was admixed with tumor and inoculated i.d. as previously determined to be the optimal regimen for pre-effector cell sensitization $[23,24]$. TDLN cells were prepared in a single-cell suspension by teasing apart the lymph nodes with 20 -gauge needles and then pressing the lymph node with the blunt end of a $10-\mathrm{ml}$ plastic syringe.

\section{In vitro anti-CD3/IL-2 activation}

TDLN cells were activated for 2 days in anti-CD3 monoclonal antibody immobilized in 24 -well tissue-culture plates at $4 \times 10^{6}$ cells/ well as previously described [15]. Anti-CD3 is a hamster monoclonal antibody directed against the CD3 $\varepsilon$ epitope of the murine $\mathrm{T}$ cell receptor complex and was produced by the $2 \mathrm{C} 11$ hybridoma cell line kindly provided by Dr. Jeffrey Bluestone, University of Chicago, Ill. After anti-CD3 activation, the cells were harvested, washed, and resuspended at a concentration of $2 \times 10^{5}$ cells $/ \mathrm{ml}$ complete medium containing $60 \mathrm{U} / \mathrm{ml}$ IL-2. Human recombinant IL-2 was kindly supplied by Chiron Therapeutics (Emeryville, Calif.) with a specific activity of $18 \times 10^{6} \mathrm{IU} / \mathrm{mg}$ protein. In this report, all units of IL-2 are expressed in international units (U). After 3 days, the cells were harvested, washed, and resuspended in HBSS for adoptive immunotherapy.
Table 1 Cytokine secretion by transduced clones. All clones derived from a clone of wild-type BL6, which was documented not to secrete any of the cytokines measured above. $I L$ interleukin, IFN interferon, $G M-C S F$ granulocyte/macrophage-colony-stimulating factor

\begin{tabular}{ll}
\hline Clone Designation $^{\mathrm{a}}$ & $\begin{array}{l}\text { Cytokine } \\
\text { Secretion }\left(10^{6} \text { cells/24 h) }\right.\end{array}$ \\
\hline BL6/IL-2 & $150 \mathrm{U} / \mathrm{ml} \mathrm{IL-2}$ \\
BL6/IL-4 & $80 \mathrm{U} / \mathrm{ml} \mathrm{IL-4}$ \\
BL6/IFN $\gamma$ & $150 \mathrm{U} / \mathrm{ml} \mathrm{IFN \gamma}$ \\
BL6/GM-CSF & $450 \mathrm{ng} / \mathrm{ml} \mathrm{GM-CSF}$ \\
BL6/GM-CSF/IL-2 & $400 \mathrm{ng} / \mathrm{ml} \mathrm{GM-CSF}+150 \mathrm{U} / \mathrm{ml} \mathrm{IL-2}$ \\
BL6/GM-CSF/IL-4 & $400 \mathrm{ng} / \mathrm{ml} \mathrm{GM-CSF}+80 \mathrm{U} / \mathrm{ml} \mathrm{IL-4}$ \\
\hline
\end{tabular}

Procedure for adoptive immunotherapy

B6 mice were injected intravenously (i.v.) with $(1.5-3) \times 10^{5}$ BL6 cells in $1 \mathrm{ml} \mathrm{HBSS}$ to initiate pulmonary metastases. Four days after tumor establishment, anti-CD3/IL-2-activated lymph node cells suspended in $1 \mathrm{ml}$ HBSS were given i.v. to groups of mice comprising at least five animals. Some groups of mice were also treated with $10000 \mathrm{U}$ IL-2 in $0.5 \mathrm{ml}$ HBSS intraperitoneally (i.p.) twice a day for 4 days to enhance the in vivo proliferation and antitumor reactivity of the transferred cells. All mice were ear-tagged and randomized. Approximately 18-22 days after tumor establishment, the mice were sacrificed, the lungs insufflated with Fekete's solution, and pulmonary metastases counted without knowledge of the treatment. For all experiments, lungs with more than 250 metastatic nodules were arbitrarily assigned a value of 250 for statistical analysis.

Statistical analysis

Data from the adoptive immunotherapy studies was evaluated by the Wilcoxon rank-sum test. Two-sided $P$ values below 0.05 were considered statistically significant. No animals were excluded from the statistical analysis.

\section{Results}

\section{Establishment of cytokine-secreting clones}

Clones were isolated from a wild-type clone of BL6 after transduction with different cytokine genes using the limiting-dilution technique. Stable secretion of cytokines by these tumor clones was documented over a period of several months (Table 1). Doubly transduced tumor cells were established by utilizing the BL6/GM-CSF clone and subsequently transducing it with either the IL-2 or IL-4 retroviral vector. Clones from this second transduction were chosen to secrete equivalent amounts of cytokine to that produced by the singly transduced clones for the purposes of subsequent comparison (Table 1).

All the clones were assessed for MHC class I and II expression. The wild-type BL6 has been previously described to be poorly immunogenic and does not express either MHC class I ( $\mathrm{H}-2 \mathrm{D}^{\mathrm{b}}$ or $\left.\mathrm{H}-2 \mathrm{~K}^{\mathrm{b}}\right)$ or II $\left(\mathrm{H}-2 \mathrm{Ia}^{\mathrm{b}}\right)$ [25]. As anticipated, the BL6/IFN $\gamma$ demonstrated significant expression of both MHC class I and II molecules (Fig. 2). Neither of the other singly or doubly transduced cytokine-secreting clones expressed MHC molecules (data not shown). 


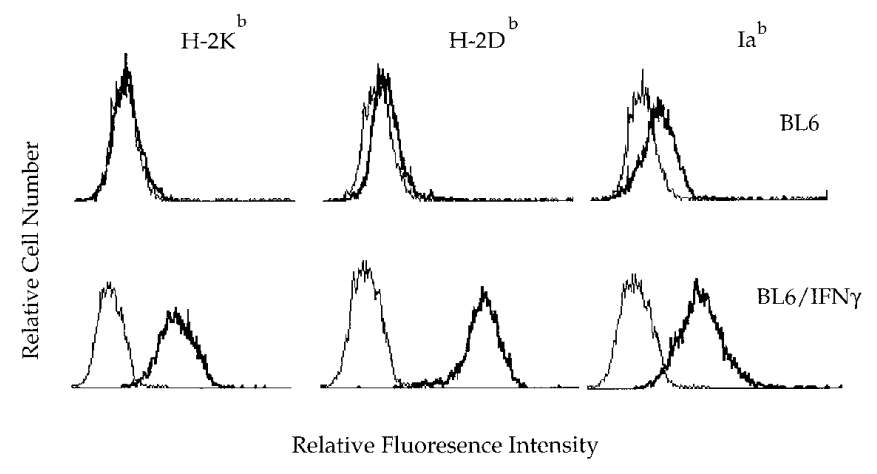

Fig. 2 MHC class I (H-2 $\mathrm{K}^{\mathrm{b}}$ and $\left.\mathrm{H}-2 \mathrm{D}^{\mathrm{b}}\right)$ and class II $\left(\mathrm{H}-2 \mathrm{Ia}^{\mathrm{b}}\right)$ expression of wild-type BL6 (light histogram) and BL6/IFN $\gamma$ (dark histogram) tumor cells

\section{Tumorigenicity}

The in vivo growth potential of each transduced clone was assessed in groups of five animals. A $10^{6}$ intradermal inoculum of wild-type BL6 into the midline of the abdominal wall grew steadily, causing predictable mortality from tumor burden at 21-25 days (Fig. 3). BL6/GM-CSF was not significantly different in tumorigenicity compared to wild-type tumor. BL6/IL-4 and BL6/IFN $\gamma$ manifested considerably slower rates of tumor growth; however, all animals eventually succumbed to tumor. BL6/IL-2 demonstrated the greatest reduction in tumorigenicity with two of five animals having rejected the tumor completely by day 35. Of note: subsequent challenge of these tumor-free mice with wild-type BL6 resulted in tumor growth without evidence of immunity.

The tumorigenicity of the doubly transduced clones was also assessed (Fig. 4). BL6/GM-CSF/IL-4 was not significantly different in growth compared with the BL6/IL-4. Hence, there was no synergy between these two cytokines in altering tumorigenicity. Similarly, the tumorigenicity of BL6/GM-CSF/IL-2 was not significantly different from that of the BL6/IL-2. None of the animals inoculated with BL6/

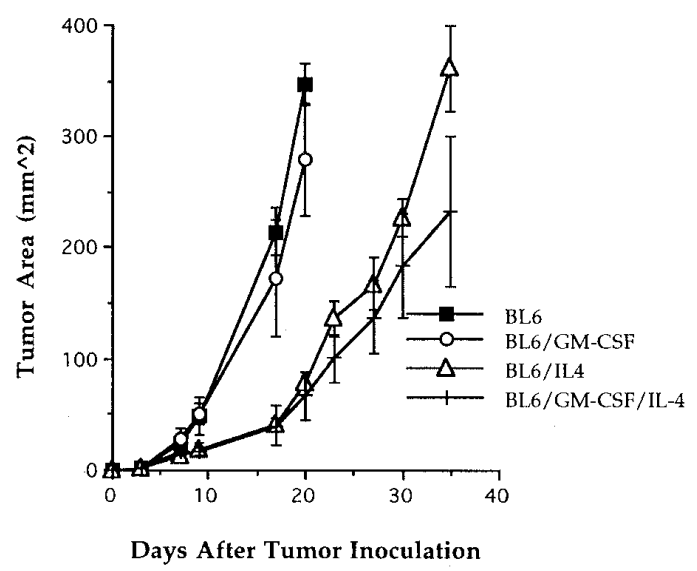

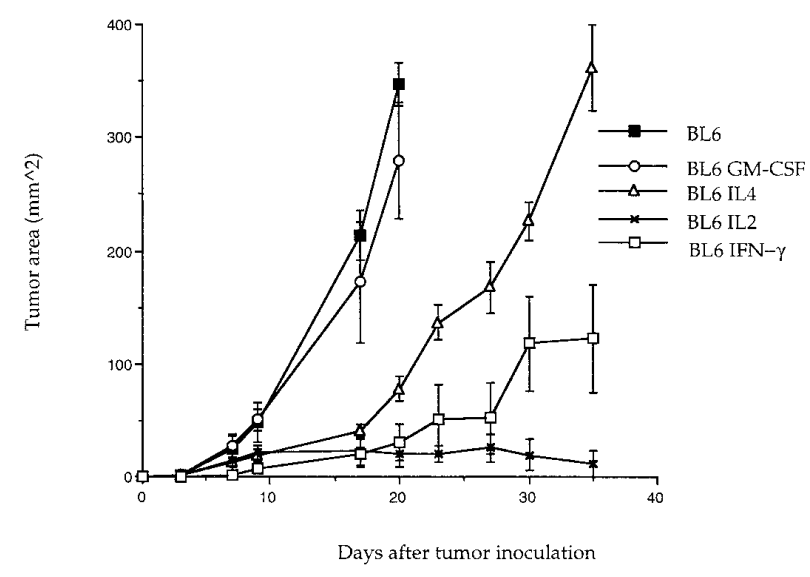

Fig. 3 Tumor growth curves of BL6, BL6/IL-2, BL6/IFN $\gamma$, BL6/IL-4 and BL6/GM-CSF. Mean tumor areas \pm SEM are plotted

GM-CSF/IL-2 completely rejected the tumor inoculum in contrast to four of five animals inoculated with BL6/IL-2.

Use of cytokine-secreting tumor cells as vaccines

One approach to assessing the immunogenicity of a tumor is to evaluate the ability to induce systemic immunity by vaccinating naive mice and challenging the animals with viable tumor at a defined interval. Irradiated (50 Gy) wildtype BL6 (106 cells) when inoculated i.d. does not grow and did not protect animals from viable wild-type ( $10^{5}$ cells) tumor challenge given i.d. 4 weeks later at a separate site (Fig. 5). We have previously evaluated a potent bacterial adjuvant, $C$. parvum, which was admixed with BL6 as a vaccine and failed to generate systemic immunity [20]. Hence, we have classified this tumor as poorly immunogenic. In six separate experiments, groups of mice were inoculated with irradiated wild-type tumor or the transduced clones. These animals, along with a normal, non-

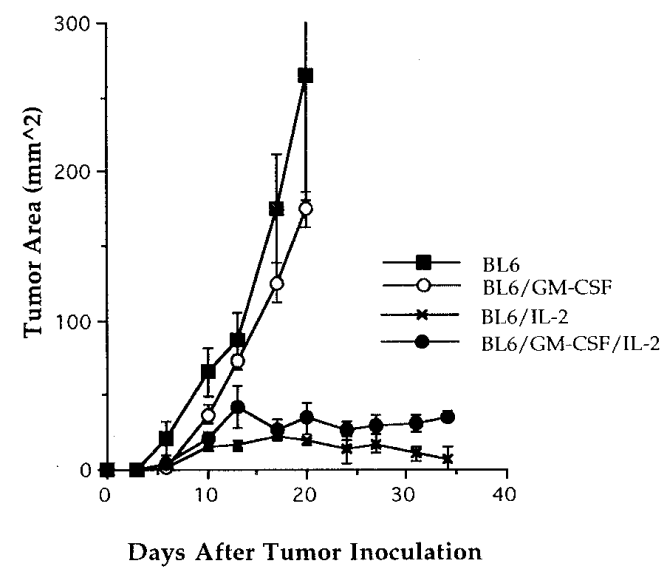

Fig. 4 Tumor growth curves of doubly transduced tumor clones compared with the relevant singly transduced tumor clones. Mean tumor areas \pm SEM are plotted 

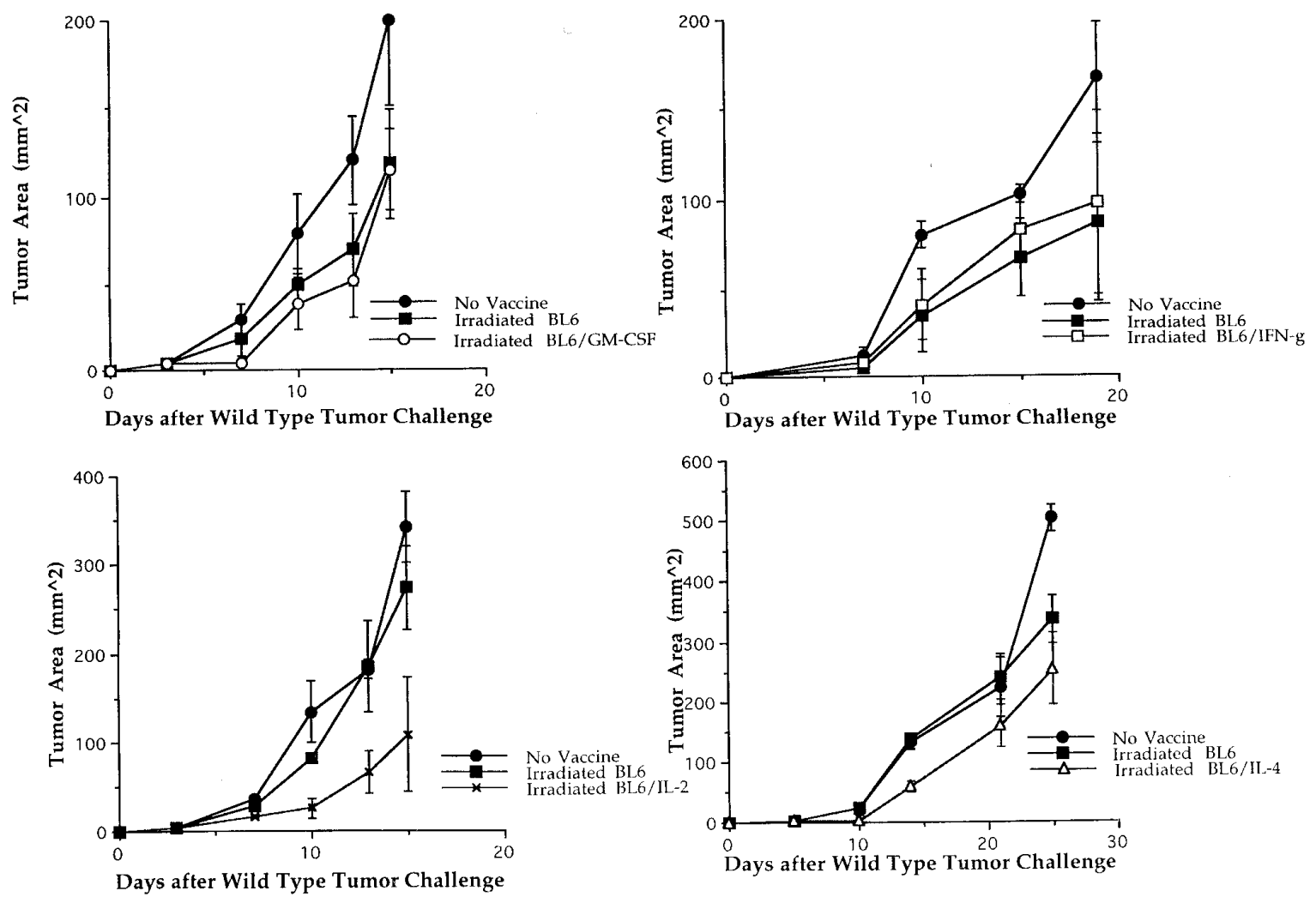

vaccinated group of mice, were subsequently challenged with wild-type tumor. Figure 5 shows that there was no difference in the growth of the tumor-challenge inocula in mice vaccinated with BL6/GM-CSF or BL6/IFN $\gamma$ tumor compared to wild-type tumor. There was a noticeable decrease in tumor growth of the tumor-challenge inocula in mice vaccinated with BL6/IL-2 or BL6/IL-4 compared to wild-type tumor vaccination; however, all the mice succumbed to progressive tumor.

Figure 6 shows that the decreased growth of a subsequent tumor challenge induced by vaccination with BL6/ IL-2 or BL6/IL-4 was reproduced and compared with that in mice vaccinated with doubly transduced tumor cells. Tumor-challenge inocula had a marked decrease in growth after vaccination with the BL6/GM-CSF/IL-4 cells compared to the BL6/IL-4. The previous studies (Fig. 5) had demonstrated that vaccination with BL6/GM-CSF did not result in decreased tumorigenicity of a subsequent tumor challenge. Hence, the vaccination results with BL6/GMCSF/IL-4 suggested a synergistic effect between the two cytokines. Nevertheless, all mice vaccinated with BL6/GMCSF/IL-4 cells developed tumors that ultimately led to their demise. There was no additive or synergistic effect noted after immunization with the doubly transduced BL6/GMCSF/IL-2 clone in the induction of immunity compared with BL6/IL-2.

\section{Phenotypic characterization of TDLN cells}

The phenotype of freshly harvested TDLN cells draining 9day intradermal flank tumors was evaluated by flow cyto-

Fig. 5 Growth curves of wild-type tumor challenge after vaccination with irradiated wild-type tumor or cytokine-secreting tumor cells. Mean tumor areas \pm SEM are plotted

metry. There were no appreciable differences in the percentage of $\mathrm{CD}^{+}+$or $\mathrm{CD} 8+\mathrm{T}$ cells between the wild-type tumor or any of the singly transfected tumors (data not shown). We examined the expression of B7-1, a co-stimulatory molecule associated with antigen-presenting cells and their state of activation $[4,5]$. There was no appreciable difference in B7-1 expression by TDLN cells from animals inoculated with wild-type tumor, BL6/IL-2, BL6/IFN $\gamma$ or BL6/IL-4 with positive cells ranging from $1 \%$ to $9 \%$. However, there was a noticeable increase in expression of B7-1 in mice inoculated with BL6/GM-CSF with $15 \%$ of the cells staining positively compared with wild-type BL6 (Fig. 7).

Therapeutic efficacy of TDLN cells in an adoptive-transfer model

In 13 separate experiments, TDLN cells harvested from animals inoculated i.d. with single-cytokine-secreting tumors were used to treat animals bearing 4-day established wild-type BL6 pulmonary metastases. Prior to adoptive transfer, the cells were activated by the anti-CD3/IL-2 culture method, which we have previously described. The reduction of lung tumors at the end of the observation period allowed quantification of any antitumor effect of the 

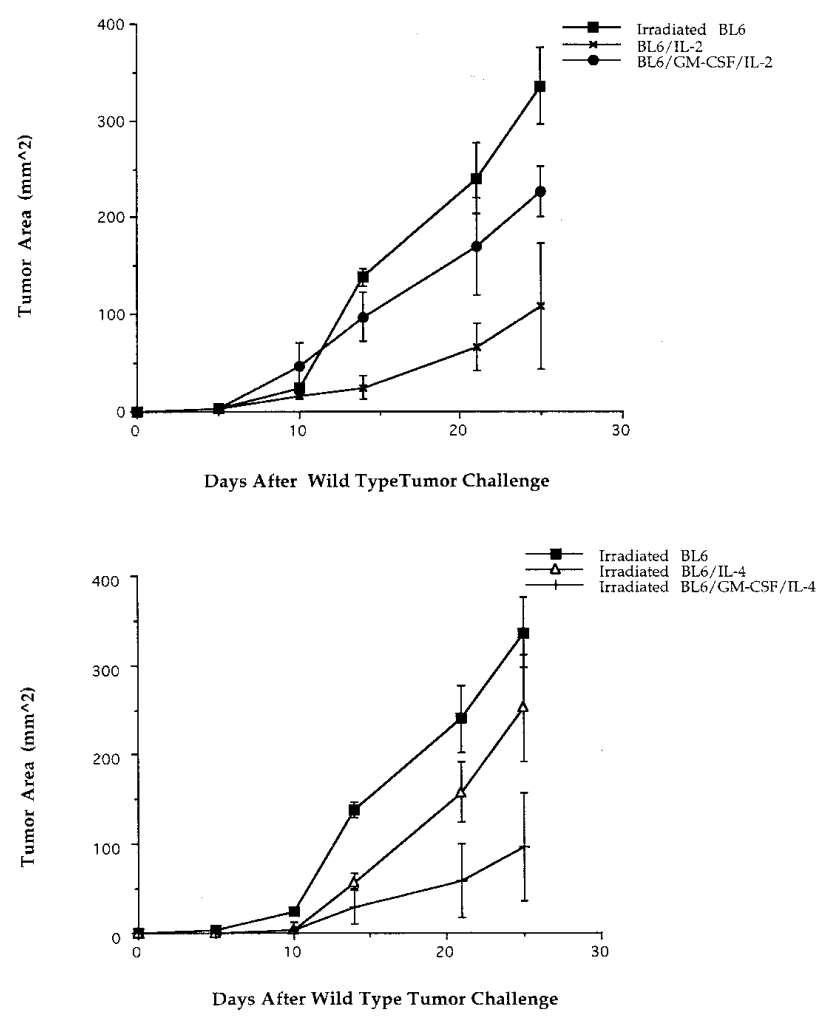

Fig. 6 Growth curves of wild-type tumor challenge after vaccination with irradiated wild-type tumor or doubly-cytokine-secreting tumor cells. Mean tumor areas \pm SEM are plotted

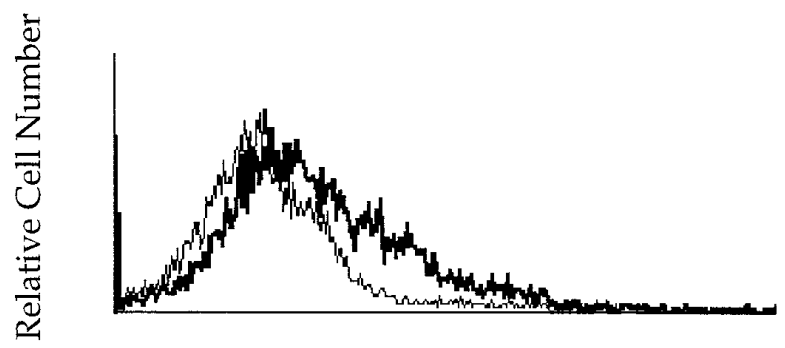

Relative Fluoresence Intensity

Fig. 7 Enhanced B7-1 expression by freshly harvested tumor-draining lymph node (TDLN) cells from BL6/GM-CSF (dark histogram) compared with wild-type tumor (light histogram).

transferred cells. The antitumor reactivity mediated by TDLN cells from mice inoculated with cytokine-secreting tumors was compared to the mean number of lung metastases of mice that received no cells, and allowed a calculation of the percentage reduction of lung metastases for each experimental group (Fig. 8). The secretion of GM-CSF was consistently superior in the induction of tumor-reactive cells which could be retrieved in the TDLN. The secretion of IL-2 and IFN $\gamma$ was not effective in eliciting tumorreactive TDLN cells. IL-4 secretion was comparable to $C$. parvum as an immunological adjuvant, but neither was as effective as GM-CSF in sensitizing TDLN effector cells. The antitumor reactivity mediated by lymph-node draining

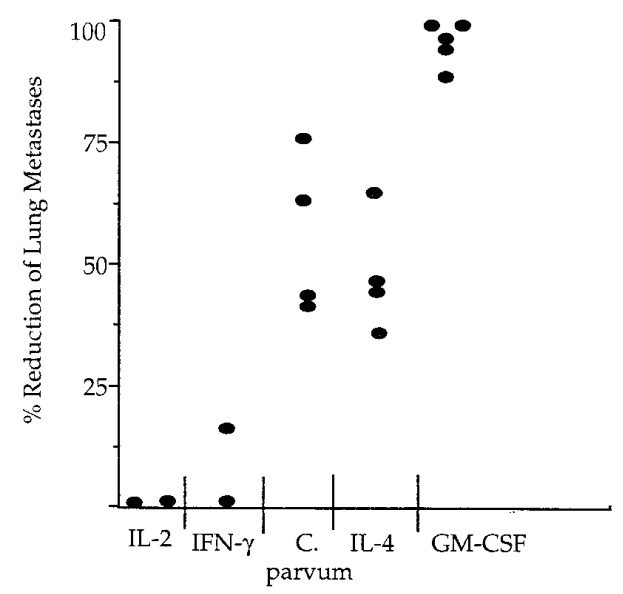

Fig. 8 Percentage reduction of pulmonary metastases by TDLN derived from animals inoculated with cytokine-secreting tumors or BL6 admixed with $C$. parvum. Each dot represents a separate experiment

BL6/GM-CSF was immunologically specific since they were incapable of causing regression of similarly established MCA 205, a methylcholanthrene-induced sarcoma (data not shown).

We also examined the ability of doubly transfected BL6 tumor cells to sensitize TDLN. Both double transfectants secreted GM-CSF, which was the most effective cytokine identified in the studies of single-cytokine-secreting cells. The addition of IL- 2 or IL-4 was evaluated in combination with GM-CSF. As noted in Table 2, IL-2-secreting tumor cells did not elicit tumor-reactive TDLN, while GM-CSFsecreting tumor cells were successful. The doubly transduced BL6 cells secreted equivalent amounts of cytokine compared to the single transfectants, and were no better than BL6/GM-CSF at sensitizing the draining lymph node. In another experiment (Table 3), BL6/IL-4, BL6/GM-CSF and BL6/GM-CSF/IL-4 were evaluated. As previously documented both IL-4 and GM-CSF secretion induced tumor-reactive TDLN cells with GM-CSF being superior to IL-4. However, the combination of GM-CSF and IL-4

Table 2 Adoptive immunotherapy of pulmonary metastases using tumor-draining lymph nodes $(T D L N)$ from mice inoculated with transduced tumor secreting GM-CSF and IL-2. Mice with 4-day established wild-type BL6 pulmonary metastases received $6 \times 10^{7}$ cells i.v. Some groups also received IL-2 60000 IU i.p. twice daily for 4 days

\begin{tabular}{|c|c|c|c|}
\hline \multirow[t]{2}{*}{ Group } & \multicolumn{2}{|l|}{ Treatment ${ }^{\mathrm{a}}$} & \multirow{2}{*}{$\begin{array}{l}\text { Mean no. of pulmonary } \\
\text { metastases (SEM) }\end{array}$} \\
\hline & Source of TDLN cells & IL-2 & \\
\hline $\mathrm{A}$ & None & - & $>250$ \\
\hline B & None & + & $>250$ \\
\hline $\mathrm{C}$ & BL6 & + & $>250$ \\
\hline $\mathrm{D}$ & BL6/IL-2 & + & $>250$ \\
\hline $\mathrm{E}$ & BL6/GM-CSF & + & $31(26)^{*}$ \\
\hline $\mathrm{F}$ & BL6/GM-CSF/IL-2 & + & $107(56)^{* *}$ \\
\hline
\end{tabular}

$* P<0.001$ compared to groups A-D

** $P<0.05$ compared to groups $\mathrm{A}-\mathrm{D}$ 
Table 3 Adoptive immunotherapy of pulmonary metastases using TDLN from mice inoculated with transduced tumor secreting GMCSF and IL-4. The treatment protocol is identical to that described in Table 1

\begin{tabular}{llll}
\hline Group & \multicolumn{2}{l}{ Treatmenta } & $\begin{array}{l}\text { Mean no. of pulmonary } \\
\text { metastases (SEM) }\end{array}$ \\
\cline { 2 - 3 } & Source of TDLN cells & IL-2 & \\
\hline A & None & - & $>250$ \\
B & None & + & $>250$ \\
C & BL6 & + & $>250$ \\
D & BL6/IL-4 & + & $165(44) *$ \\
E & BL6/GM-CSF & + & $16(8)^{* *}, * * *$ \\
F & BL6/GM-CSF/IL-4 & + & $36(35)^{* *}, * * *$ \\
\hline
\end{tabular}

$* P<0.02$ compared to groups $\mathrm{A}-\mathrm{C}$

** $P<0.001$ compared to groups A-C

$* * * P<0.03$ compared to group D

secretion was no better than GM-CSF alone. Hence, there was no evidence of any additive or synergistic effect of IL-2 or IL-4 combined with GM-CSF in the induction of tumorreactive TDLN.

\section{Discussion}

There has been a significant body of information reported on the genetic modification of murine tumors, which suggests that gene transfer may offer new approaches to immunotherapy [26, 27]. A plethora of immunoregulatory peptides, which include cytokines and co-stimulatory molecules, have been evaluated by gene transfer into tumors. It has been difficult to draw conclusions regarding the utility of these observations because of the diversity of tumors utilized and the different immune parameters that have been measured. The inherent immunogenicity of the tumor can significantly influence the immunobiology of the cellular genetic constructs being examined. For example, Chen et al. demonstrated that the ability to vaccinate normal mice successfully with a series of weakly immunogenic murine tumors transduced with the B7-1 co-stimulatory molecule was not reproducible in non-immunogenic tumors [2]. Other issues that have not been clearly defined are the clinical correlates that can be drawn from the available animal models. It is not clear whether reduced tumorigenicity of a genetically modified tumor will translate into a clinically effective vaccine.

We chose a murine tumor that has many attributes associated with human cancers. The BL6 tumor is poorly immunogenic on the basis of its lack of MHC class I or II molecule expression [1, 2], refractoriness to IL-2 therapy [1], inability to induce systemic immunity by vaccination [20], and inability to elicit functional TIL or tumor-reactive draining lymph node cells [19, 23, 24]. In addition, this tumor will give rise to spontaneous visceral metastases from an intradermal tumor inoculum [24]. With this tumor, we demonstrated that IL-2, IL-4 and IFN $\gamma$ secretion will reduce the tumorigenicity of the transfectant and, in the case of IL-2 secretion, result in complete tumor regression. However, mice that rejected IL-2-secreting cells were not immune to a challenge from the wild-type tumor. Moreover, the vaccination of mice with irradiated cytokine-secreting BL6 tumor cells was unsuccessful in eliciting protective systemic immunity to a subsequent challenge of wild-type tumor. The finding that vaccination with IL-2- or IL-4secreting cells retarded the growth of a subsequent tumor challenge suggested an incomplete protective response. These studies demonstrated that BL6 is an aggressive poorly immunogenic tumor.

Despite the seemingly disappointing results regarding the establishment of systemic immunity, the vaccination/ challenge model may not necessarily reflect the therapeutic potential of cytokine-secreting vaccines in a micrometastatic disease state. The ability to reject an intradermal inoculum of $10^{5}$ cells represents a significant tumor load at one site. A more appropriate and clinically relevant approach is to examine the efficacy of vaccinating animals with cytokine-secreting tumor cells in a setting of spontaneous micrometastatic disease. The BL6 tumor model is ideal for this situation in which an intradermal inoculum of wild-type tumor can be allowed to grow and then be surgically removed. We have found that animals will subsequently succumb to distant metastatic disease approximately 40 days after the primary tumor excision [24]. Vaccination with cytokine-secreting tumor cells may offer some advantage to wild-type tumor as adjuvant therapy for micrometastatic disease.

We have utilized the adoptive transfer of TDLN cells to treat mice with established multiple lung metastases. We have previously reported that BL6 TDLN cells are not adequately sensitized to mediate tumor regression upon adoptive transfer [23, 24]. However, the admixture of a bacterial adjuvant with viable or irradiated BL6 was capable of eliciting tumor-reactive cells in the draining lymph node, and indicated that the wild-type tumor expressed epitopes capable of being recognized by immune $\mathrm{T}$ cells in a rejection response. This has afforded us a model to evaluate the ability of cytokine-secreting BL6 cells to induce tumor-reactive $\mathrm{T}$ cells. Our studies demonstrated that GM-CSF and IL-4 elaboration were capable of eliciting immune $\mathrm{T}$ cells in the draining lymph node with GM-CSF being superior to IL-4 as well as the admixture of $C$. parvum. We utilized the optimal dose of $C$. parvum in these experiments, which we had previously defined in an earlier report [7]. The superiority of GM-CSF to IL-4 may represent a quantitative difference related to the amount of cytokine elaboration. The maximal amount of GM-CSF or IL-4 cytokine for elicitating immune TDLN cells has not been defined. Interestingly, the combination of IL-4 was not additive to GM-CSF secretion, which suggested that these cytokines may have a similar mechanism involved in the induction of immune T cells. The complete lack of immune TDLN induction by IL-2 or IFN $\gamma$ secretion, which reduced tumorigenicity, indicated that increasing levels of secretion would most likely not be productive. These observations indicate that Th1 cytokines are not critical in the afferent phase of the lymph node response to BL6. By contrast, the 
evidence that IL-2 and IFN $\gamma$ resulted in decreased tumorgenicity of BL6 indicated that a different host response was involved. We have previously documented that IL-2 and IL4 secretion by BL6 tumor cells completely abrogated tumorigenicity and that this was not mediated by $\mathrm{T}$ cells since the phenomenon was also observed in irradiated hosts [24].

We hypothesize that GM-CSF and possibly IL-4 augment $\mathrm{T}$ cell sensitization in the draining lymph node by recruiting and activating APC in the local tumor site and regional nodal basin. GM-CSF and IL-4 appear to support the growth of dendritic cells with expression of MHC class II and B7. Sallusto and Lanzavecchia reported that GMCSF and IL-4 provided optimal conditions for dendritic cells to present soluble antigen to $\mathrm{T}$ cells [21]. We have previously shown that BL6/GM-CSF tumors induce significantly higher numbers of CD11b-positive cells in the draining lymph node [15]. In this study, we found that the expression of B7-1 was also up-regulated in TDLN cells, which may reflect the larger number of APC and/or their activation state. The inability to document B7-1 up-regulation in the TDLN of BL6/IL-4 inoculums may be a quantitative effect of the amount of cytokine elaborated.

We have initiated a clinical trial to evaluate the use of GM-CSF-secreting autologous tumor cells to prime draining lymph node in melanoma patients. The primed lymph node cells will be evaluated for in vitro tumor reactivity as well as in vivo therapeutic efficacy in adoptive transfer. On the basis of our pre-clinical model, the use of GM-CSFsecreting tumor cells appears to offer an advantage to bacterial adjuvants as a vaccine.

In summary, cytokine-secreting tumors can mediate diverse immunological responses when inoculated in the immunocompetent host. Utilizing a poorly immunogenic tumor, we have demonstrated that different cytokines resulted in distinctly different immune responses. Reduced tumorigenicity did not directly correlate with the induction of systemic immunity as assessed by protection against wild-type tumor challenge, nor did it correlate with the generation of tumor-reactive lymph node cells.

Acknowledgements This work was supported in part by NIH grants PO1 CA59327 (A.E.C.), T32 CA09672 (M.J.A., S.S.) and the Gillson Longenbaugh Foundation. Dr. Chang is the recipient of an American Cancer Society Faculty Award. The authors wish to acknowledge the excellent assistance of Ms. Debbie Birdsall in the preparation of this manuscript.

\section{References}

1. Arca MJ, Krauss JC, Aruga A, Cameron MJ, Shu S, Chang AE (1996) Therapeutic efficacy of T cells derived from lymph nodes draining a poorly immunogenic tumor transduced to secrete GMCSF. Cancer Gene Therapy 3:39

2. Chen L, McGowan P, Ashe S, Johnston J, Li Y, Hellstrom I, Hellstrom KE (1994) Tumor immunogenicity determines the effect of B7 costimulation on T cell mediated tumor immunity. J Exp Med 179:523
3. Dranoff G, Jaffee E, Lazenby A, Golumbek P, Levitsky H, Brose K, Jackson V, Hamada H, Pardoll D, Mulligan RC (1993) Vaccination with irradiated tumor cells engineered to secrete murine granulocyte-macrophage colony stimulating factor stimulates potent, specific, and long-lasting anti-tumor immunity. Proc Natl Acad Sci USA 90:3539

4. Fearon ER, Pardoll DM, Itaya T, Golumbek P, Levitsky HI, Simons JW, Karasuyama H, Vogelstein B, Frost P (1990) Interleukin-2 production by tumor cells bypasses $\mathrm{T}$ helper function in the generation of an antitumor response. Cell 60:397

5. Gansbacher B, Bannerji R, Daniels B, Zier K, Cronin K, Gilboa E (1990) Retroviral vector-mediated $\gamma$-interferon gene transfer into tumor cells generates potent and long lasting antitumor immunity. Cancer Res 50:7820

6. Geiger JD, Wagner PD, Shu S, Chang AE (1992) A novel role of autologous tumour cell vaccination in the immunotherapy of the poorly immunogenic B16-BL6 melanoma. Surg Oncol 1:199

7. Geiger JD, Wagner PD, Cameron MJ, Shu S, Chang AE (1993) Generation of $\mathrm{T}$ cells reactive to the poorly immunogenic B16BL6 melanoma with efficacy in the treatment of spontaneous metastases. J Immunother 13:153

8. Geraghty PJ, Chang AE (1995) Basic principles associated with gene therapy of cancer. Surg Oncol 4:125

9. Ghosh P, Komschlies KL, Cippitelli M, Longo DL, Subleski J, Ye J, Sica A, Young HA, Wiltrout RH, Ochoa AC (1995) Gradual loss of $\mathrm{T}$ helper 1 populations in spleen of mice during progressive tumor growth. J Natl Cancer Inst 87:1478

10. Hart IR (1979) The selection and characterization of an invasive variant of the B16 melanoma. Am J Pathol 97:587

11. Inge TH, Hoover SK, Susskind BM, Barrett SK, Bear HD (1992) Inhibition of tumor-specific cytotoxic T lymphocyte responses by transforming growth factor $\beta 1$. Cancer Res 52:1386

12. Kim J, Modlin RL, Moy RL, Dubinett SM, McHugh T, Nickoloff BJ, Uyemura K (1995) IL-10 production in cutaneous basal and squamous cell carcinomas. J Immunol 155:2240

13. McDougall CJ, Ngoi SS, Goldman IS, Godwin T, Felix J, DeCosse JJ, Rigas B (1990) Reduced expression of HLA Class I and II antigens in colon cancer. Cancer Res 50:8023

14. Miller AR, McBride WH, Hunt K, Economou JS (1994) Cytokinemediated gene therapy for cancer. Ann Surg Oncol 1:436

15. Mizoguchi H, O'shea JJ, Longo DL, Loeffler CM, McVicar DW, Ochoa AC (1992) Alterations in signal transduction molecules in T lymphocytes from tumor-bearing mice. Science 258:1795

16. Nathanson SD, Haas GP, Mead MJ, Lee M (1986) Spontaneous regional lymph node metastases of three variants of the B16 melanoma: Relationship to primary tumor size and pulmonary metastases. J Surg Oncol 33:41

17. Nestle FO, Buchner S, Nickoloff B, Burg G (1995) Induction of co-stimulatory molecules CD80 (B7-1) and CD86 (B7-2) on peritumoral antigen-presenting cells in basal cell carcinomas treated with IFN-alpha. J Invest Dermatol 105:492

18. Nestle FO, Burg G, Fäh J, Nickoloff B (1996) In vivo and in vitro characterization of human tumor associated dendritic cells: deficiency in $\mathrm{T}$ cell co-stimulatory molecules and impaired antigenpresenting function

19. Porgador A, Bannerji R, Watanabe Y, Feldman M, Gilboa E, Eisenbach L (1993) Antimetastatic vaccination of tumor-bearing mice with two types of IFN- $\gamma$ gene-inserted tumor cells. J Immunol 150: 1458

20. Restifo NP, Spiess PJ, Karp SE, Mul JJ, Rosenberg SA (1992) A nonimmunogenic sarcoma transduced with the cDNA for interferon $\gamma$ elicits CD8+ $\mathrm{T}$ cells against the wild type tumor: correlation with antigen presentation capability. J Exp Med 175:1423

21. Sallusto F, Lanzavecchia A (1994) Efficient presentation of soluble antigen by cultured human dendritic cells is maintained by granulocyte/macrophage colony-stimulating factor plus interleukin 4 and downregulated by tumor necrosis factor $\alpha$. J Exp Med 179:1109

22. Salvadori S, Gansbacher B, Pizzimenti AM, Zier KS (1994) Abnormal signal transduction by $\mathrm{T}$ cells of mice with parental tumors is not seen in mice bearing IL-2 secreting tumors. J Immunol 153:5176 
23. Strome SE, Krauss JC, Cameron MJ, Forslund K, Shu S, Chang AE (1993) Immunobiologic effects of cytokine gene transfer of the B16-BL6 melanoma. Arch Otolaryngol Head Neck Surg 119:1289

24. Strome SE, Chang AE, Shu S, Krauss JC (1996) Secretion of both IL-2 and IL-4 by tumor cells results in rejection and immunity. J Immunother 19: 21

25. Tahara H, Zitvogel L, Storkus WJ, Zeh HJ, McKinney TG, Schreiber RD, Gubler U, Robbins PD, Lotze MT (1995) Effective eradication of established murine tumors with IL-12 gene therapy using a polycistronic retroviral vector. J Immunol 154:6466

26. Tanaka K, Gorelik E, Watanabe M, Hozumi N, Jay G (1988) Rejection of B16 melanoma induced by expression of a transfected major histocompatibility complex class I gene. Mol Cell Biol $8: 1857$
27. Weber JS, Rosenberg SA (1990) Effects of murine tumor class I major histocompatibility complex expression on antitumor activity of tumor-infiltrating lymphocytes. J Natl Cancer Inst 82:755

28. Weber JS, Jay G, Tanaka K, Rosenberg SA (1987) Immunotherapy of a murine tumor with interleukin-2. Increased sensitivity after MHC class I gene transfection. J Exp Med 166:1716

29. Zea AH, Curti BD, Longo DL, Alvord WG, Strobl SL, Mizoguchi H, Creekmore SP, O'shea JJ, Powers GC, Urba WJ, Ochoa AC (1995) Alterations in $\mathrm{T}$ cell receptor and signal transduction molecules in melanoma patients. Clin Cancer Res $1: 1327$ 